\title{
International nifedipine trial on anti-atherosclerotic therapy (INTACT) - methodologic implications and results of a coronary angiographic follow-up study using computer-assisted film analysis
}

\author{
Stefan Jost, Jaap Deckers ${ }^{1}$, Wolf Rafflenbeul, Hartmut Hecker, Johan H.C. Reiber ${ }^{1}$, Peter Nikutta, \\ Birgitt Wiese, Paul Hugenholtz ${ }^{1}$, Paul Lichtlen \& the INTACT-Group \\ Department of Cardiology, Hannover Medical School, Hannover, Germany and ${ }^{1}$ Thorax Center, \\ Erasmus University, Rotterdam, The Netherlands
}

Key words: INTACT, nifedipine, coronary artery disease, quantitative coronary angiography, progression, atherosclerosis

\begin{abstract}
Animal experiments demonstrated a significant suppressive effect of various calcium channel blockers on the formation of atherosclerotic lesions. Therefore, a prospective, placebo-controlled, randomized, double blind multicenter study was performed to investigate the inhibitory influence of the calcium channel blocker nifedipine ( $80 \mathrm{mg} /$ day) on the progression of coronary artery disease in man. Study endpoints were changes of coronary morphology documented by coronary angiography with particular respect to the formation of new coronary stenoses. In 348 out of 425 patients included in the study, coronary angiograms were repeated after three years. The angiograms were standardized by induction of a maximal coronary vasodilation with high doses of nitrates and by using absolutely identical angiographic projections. Quantitative analysis of coronary cineangiograms was performed with the computer-assisted contour detection system CAAS. Parameters were mean and minimal diameter of all segments and minimal stenosis diameter, percent diameter stenosis, length and plaque area of all stenoses.

Continuous intake of study medication was registered in 282 patients, 134 on nifedipine and 148 patients on placebo. In these patients, a total of 3808 coronary segments with 893 stenoses $(\geqslant 20 \%$ diameter reduction in at least one angiographic projection) were compared on the baseline and follow-up cineangiograms. The changes in all angiographic parameters analyzed averaged over all patients by considering all angiographic projections analyzed, indicated significant progression of the disease $(p<0.006)$. The average changes in all parameters were even about three times more profound, when in the individual patients only the respective projections indicating the maximal changes were considered for the calculation $(p<0.001)$. However, with neither of these two analysis modes, the differences in progression between the treatment groups were statistically significant.

In the follow-up angiograms, a total of 196 new coronary lesions ( 185 stenoses, 11 occlusions) were found at previously normal arterial sites. In patients on nifedipine, an average of only 0.58 new lesions per patient were detected versus 0,80 lesions per patient on placebo $(-27 \% ; p=0.031)$.

INTACT is the first prospective angiographic trial on the progression of coronary artery disease using computer-assisted quantitative coronary angiography in such a high number of patients. All parameters analyzed indicated significant progression of coronary artery sclerosis. Nifedipine had no influence on the progression of preexisting coronary stenoses, but inhibited significantly the formation of new angiographically recognizable lesions. Further prospective coronary angiographic trials with calcium channel blockers using a comparably exact method are needed to confirm the results of this study.
\end{abstract}




\section{Introduction}

Studies on the long-term effects of diet or drugs on the progression of coronary artery disease defining clinical endpoints (e.g. myocardial infarction, cardiac death) require observation of thousands of patients over a period of many years [1-9]. Thanks to the continuous improvement in the quality of coronary angiograms over the past two decades, it has become feasible to define primary angiographic study endpoints. With such an angiographic trial design, the number of patients to be included can be reduced to a few hundred patients and the follow-up period can be limited to a few years [10-17]. One major problem of an angiographic determination of the progression of coronary atherosclerosis is the mode of analysis of the cinefilms. Repeated assessment of the severity of coronary artery disease by a panel of experienced cardiologists has been shown to be associated with a marked variability [18-21]. Therefore, quantitative methods, today mostly assisted by a computer, were introduced to improve the objectivity and reproducibility of the assessment of coronary dimensions [11, 22-24]. With these tools, the variability of the results of repeated measurements of coronary artery dimensions could be substantially reduced [24].

In the following, the results of the INTACT follow-up trial will be presented; in this study the influence of the calcium channel blocker nifedipine on the progression of coronary artery disease was studied over a period of three years. The endpoints of the study were defined by changes in angiographic parameters, which were analyzed with the computer-assisted contour detection system CAAS (Coronary Angiography Analysis System) [23-26]. INTACT - International Nifedipine Trial on Antiatherosclerotic Therapy - was initiated, after animal experiments had suggested an inhibitory effect of various calcium channel blockers on the formation of early atherosclerotic lesions caused by an atherogenic diet [27-30]. Therefore, in INTACT, particular attention was directed to the detection of newly formed coronary stenoses in the follow-up angiograms.

\section{Study design}

INTACT is a prospective, placebo-controlled, randomized, double blind, international multicenter study. From November 1983 to June 1985, a total of 425 patients with preferably early stages of coronary artery disease were included in six hospitals in the Federal Republic of Germany and in three hospitals in The Netherlands. Two hundred and fourteen patients were randomized to nifedipine, 211 to placebo. Inclusion and exclusion criteria of the study have been published in detail [31-36]. Inclusion of patients with previous coronary angioplasty or single bypass graft implantation was allowed. Main emphasis was focussed on the presence of numerous angiographically normal coronary segments. In all patients, high quality angiograms with multiple projections of the left and right coronary arteries were mandatory. Number and angles of the angiographic projections were the responsibility of the individual centers; they also decided, whether the film quality was sufficient to include a patient in the study. Therefore, the number of projections being qualified for quantitative analysis varied among the individual films and among the centers [32].

The rotations and angulations of all angiographic projections used were noted in a special protocol. After the three-years-treatment period, a followup angiogram with the same angiographic projections as on the baseline angiogram concluded the study. In order to eliminate potential coronary spasm and to induce profound coronary dilation, $10 \mathrm{mg}$ isosorbide dinitrate were administered 10 minutes prior to all angiograms $[37,38]$. To avoid influences from other vasodilating drugs, any vasoactive substances (incl. nifedipine) except nitroglycerin administered sublingually were withheld two days before angiography. All angiographic and clinical baseline data (number of coronary stenoses and occlusions, coronary risk factors, previous myocardial infarctions, previous PTCA, angina pectoris etc.) were not different between the two treatment groups (for details see 35,36 ). 
Analysis of cinefilms

The angiograms were evaluated either in Hannover or in Rotterdam using identical CAAS systems [23-26]. At the beginning of each film analysis, two experienced cardiologists, who were unaware of the patient's drug regimen, selected appropriate projections, cineframes and coronary segments using standard Tagarno cinefilm projectors. Paired films were viewed side by side to optimize cineframe selection. Based on the recommendations of the American Heart Association, the coronary artery tree was subdivided into 15 different segments [39]. To consider anatomic variants, an additional 10 segments were defined $[32,33,38]$. Selection criteria for the segments included: 1) major portions of the segments should run parallel to the image plane without considerable overlaps with other radio-opaque structures; and 2) segments should be maximally stretched, preferably in the end-diastolic phase of the cardiac cycle. Occluded segments, as well as segments located distal to occlusions although still opacified via collaterals, and segments of grafted arteries were not analyzed. Segments with previous angioplasty were measured, but these data will be analyzed separately.

The arrangement and contour detection algorithm of the CAAS system have been described in detail [23-25]. Following twofold optical magnification and conversion into video format with the help of a specially developed cine-video-converter (CIVICO II), regions of interest in the frames were digitized $(12 \times 512 \times 8$ bits $)$ and stored in image memory for subsequent image processing on a PDP 11/24 (Hannover) or PDP 11/44 (Rotterdam) computer system. Calibration of the frames was performed on the basis of the tip or shaft of the $8 \mathrm{~F}$ coronary contrast catheters which had been measured with a precision mechanical caliper immediately following angiography. At the beginning of each angiographic sequence, the tip and shaft of the coronary catheters had been filmed without contrast filling close to the image center. For calibration purposes the region of interest encompassing the catheter segment was magnified optically by a factor of $2 \sqrt{2}$. Pin-cushion distortion of all image intensifiers involved in the study was documented by filming a centimeter grid. All these frames were processed with a special algorithm and the corresponding correction vectors stored on the CAAS systems [23]. At the time of analysis of a coronary angiogram from a particular catheterization laboratory, the corresponding correction factors would be retrieved and applied to the detected contours of the catheter and the coronary segments.

The arterial contour detection algorithm of CAAS has been published extensively and will not be described here $[23,25]$. Of each segment, the mean diameter was computed on the basis of diameter measurements taken at increments of about $0.1 \mathrm{~mm}$ along the segment's center line [23]. The presence of a coronary stenosis was suggested by the cardiologist who inspected the film; this decision was verified with a special algorithm identifying the site of the minimal stenosis diameter. A narrowing in a segment was defined as being a stenosis, if the diameter reduction exceeded $20 \%$ in at least one angiographic view. This $20 \%$ threshold corresponds to about the threefold standard deviation of the differences in the determination of percent diameter stenosis in different cineframes $[23,25]$. The actual percent diameter stenosis was computed by comparing the minimal obstruction diameter with the interpolated reference diameter value taken at the same location and derived from the reference diameter function. This reference diameter function is a best approximation of the original size of the vessel before disease occurred and is computed on the basis of the diameters of 'normal' adjacent subsegments (23; Fig. 1). In addition, the algorithm provided data about the length of the stenosis, as well as the 'plaque area'; the area of the atherosclerotic plaque equals the area between the luminal and the reconstructed reference contours as measured over the obstructive region (Fig. 1). Data about the mean differences (accuracy) and the standard deviations (precision) of the differences of repeated measurements as assessed with the CAAS have been described elsewhere [23].

The INTACT protocol defines the following angiographic study endpoints: increase or decrease in the average and minimal diameter of a complete 


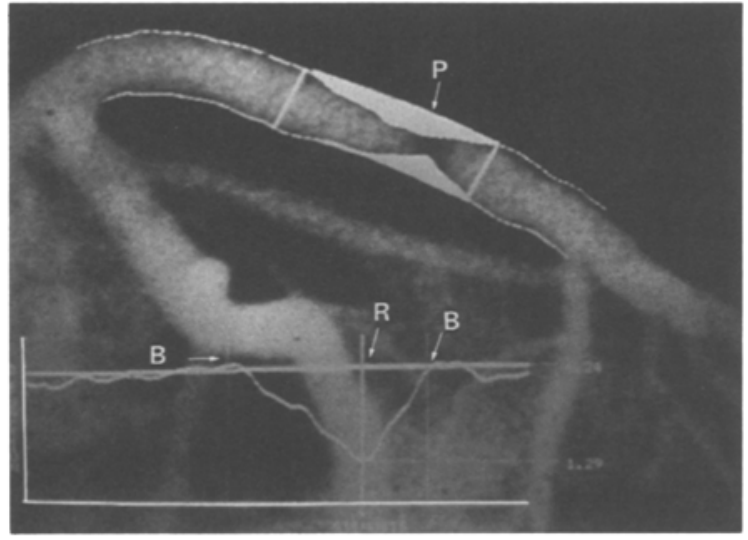

Fig. 1. Example of a CAAS-analysis of an obstructed proximal segment of the left anterior descending artery; $\mathrm{R}=$ reference diameter function; $\mathrm{B}=$ stenosis boundaries marking its length; $\mathrm{P}=$ plaque area.

coronary segment, or in the minimal stenosis diameter, in percent diameter stenosis, in stenosis length or plaque area of preexisting stenoses, as well as stenosis progression to total occlusion. Based on the known variability of the method in quantitating stenosis parameters in repeated angiograms $[23,25]$, a change in the minimal stenosis diameter of $0.4 \mathrm{~mm}$ (twofold standard deviation of the method) or more, or in the percent diameter stenosis of $\geqslant 20 \%$ (threefold standard deviation of the method) was defined as definite progression or regression of the narrowing. Formation of new stenoses (percent diameter stenosis $\geqslant 20 \%$ ) or occlusions at sites previously free from angiographically recognizable narrowings (\% diameter stenosis $<20 \%$ ) as measured by the computer algorithm was the primary end-point of progression. When new stenoses were detected in the second angiogram, the identical segment was always reanalyzed in the first angiogram to assure that no stenosis had been overseen. The average percent diameter stenosis of the new stenoses was $40 \%$ indicating that most new stenoses had undergone an increase of at least $20 \%$.

In INTACT, most segments and stenoses were analyzed in more than one angiographic projection per patient (two projections on the average); that means, that the degree of change in an angiographic segment parameter or in a stenosis parameter of an individual patient could depend on the projections which were considered. One way to minimize this projection dependency is to average the changes of a parameter over all projections in which it was analyzed in the individual patient. Another possibility would be to select only one projection from the available set which shows the largest increase or decrease in a particular parameter. Table 1 makes clear that the projections with the maximal increases or decreases in absolute diameter measurements of the coronary segments or the obstructions show the maximal regression and progression, respectively, whereas the opposite is true for the relative percent stenosis and the derived parameters length of stenosis and area plaque.

Table 1. The definition of progression or regression depends very much on the parameters and the changes in these parameters studied. For example, maximal increases or decreases in absolute diameter values of the coronary segments represent maximal regression or progression, respectively. Inversely, maximal increases or decreases in the relative percent diameter stenosis or derived length or area plaque parameters represent maximal progression or regression, respectively.

\begin{tabular}{|c|c|c|}
\hline Projection & $\begin{array}{l}\text { Maximal progression } \\
\text { (minimal regression) }\end{array}$ & $\begin{array}{l}\text { Maximal regression } \\
\text { (minimal progression) }\end{array}$ \\
\hline $\begin{array}{l}\text { Maximal increase } \\
\text { (minimal decrease) }\end{array}$ & $\begin{array}{l}\text { percent stenosis } \\
\text { length of stenosis } \\
\text { area plaque }\end{array}$ & $\begin{array}{l}\text { mean segment diameter } \\
\text { min. segment diameter } \\
\text { min. stenosis diameter }\end{array}$ \\
\hline $\begin{array}{l}\text { Maximal decrease } \\
\text { (minimal increase) }\end{array}$ & $\begin{array}{l}\text { mean segment diameter } \\
\text { min. segment diameter } \\
\text { min. stenosis diameter }\end{array}$ & $\begin{array}{l}\text { percent stenosis } \\
\text { length of stenosis } \\
\text { area plaque }\end{array}$ \\
\hline
\end{tabular}




\section{Statistics}

An inhibitory effect of nifedipine on the formation of atherosclerotic lesions has been demonstrated in numerous animal experiments $[27,29,30]$. The objective of INTACT was to test the null hypothesis, that nifedipine does not inhibit the progression of coronary atherosclerosis in man, i.e., the progression of preexisting coronary stenoses (increase of percent diameter stenosis, length or area plaque; decrease of diameter), as well as particularly the formation of new stenoses. Therefore, one-sided statistical tests were applied, when comparing the progression of preexisting coronary stenoses and the formation of new lesions between the two study groups. In all other comparisons, two-sided tests were used. For binary variables, the Chi square test was used. For discrete ordered variables with a small number of categories, Cochran's test for linear trend was applied. Other variables were analyzed with the Student t-test, using the separate variance estimation, if necessary. If more than one observation was contributed by one patient, the mixed model analysis of variance was used.

\section{Results}

Of the 425 patients included in the study, 282 pa- tients, 148 on placebo (P) and 134 on nifedipine (N), completed the study without relevant protocol violations. Protocol violations comprised termination of participation in the study or of drug intake, reduction or temporary stop of drug intake and intake of additional calcium channel blockers. Reasons for protocol violations were side effects, critical events, refusal or need for calcium blockers. Side effects of the drugs were registered in 71 patients, in 16 patients on Placebo and in 55 patients on Nifedipine $(p=0.003)$. In the patients on Nifedipine, headache, dizziness, flush, and ankle edema were the mostly reported side effects. In either treatment group, angina pectoris symptoms were slightly reduced during the study. For further informations on protocol violations and clinical follow-up see references [31, 34-36].

In the 282 patients without protocol violations (group I), the interval between the two study angiograms averaged $1123 \pm 55$ days $(\mathrm{N})$ and $1122 \pm$ 47 days $(P)$, respectively. In addition, 66 patients ( 39 on N, 27 on P) with major protocol violations underwent two angiograms after an average interval of $992 \pm 262$ days $(\mathrm{N})$ and $918 \pm 317$ days (P), respectively (group II). These patients stopped the intake of study medication after an average interval of $359 \pm 237$ days $(N)$ and $467 \pm 270$ days (P), respectively. The remaining 77 patients, 41 on $\mathrm{N}$ and 36 on $\mathrm{P}$, were lost for angiographic follow-up.

Table 2. Number of segments and lesions (stenoses and occlusions) measured in the first and second angiograms of the patients of groups $\mathrm{I}$ and II

\begin{tabular}{|c|c|c|c|c|}
\hline & Segments & Segment measurements & Proj./segment & Lesions \\
\hline \multicolumn{5}{|l|}{ Group I } \\
\hline 1. Angio & $3916(13.9 / \mathrm{pt})$ & $7950(28.3 / \mathrm{pt})$ & 2.0 & $1072(3.8 / \mathrm{pt})$ \\
\hline \multirow[t]{2}{*}{ 2. Angio } & $3808(13.5 / \mathrm{pt})$ & $7570(26.8 / \mathrm{pt})$ & 2.0 & $1230(4.4 / \mathrm{pt})$ \\
\hline & 108 lost & 420 lost & & 38 lost; 196 new \\
\hline \multicolumn{5}{|l|}{ Group II } \\
\hline 1. Angio & $929(14.1 / \mathrm{pt})$ & $1847(28.0 / \mathrm{pt})$ & 2.0 & $183(2.8 / p t)$ \\
\hline \multirow[t]{2}{*}{ 2. Angio } & $880(13.3 / \mathrm{pt})$ & $1700(25.8 / \mathrm{pt})$ & 1.9 & $225(3.4 / \mathrm{pt})$ \\
\hline & 49 lost & 147 lost & & 9 lost; 51 new \\
\hline \multicolumn{5}{|c|}{ Group I + group II } \\
\hline 1. Angio & $4845(13.9 / \mathrm{pt})$ & $9837(28.3 / \mathrm{pt})$ & 2.0 & $1255(3.6 / \mathrm{pt})$ \\
\hline \multirow[t]{2}{*}{ 2. Angio } & $4688(13.5 / \mathrm{pt})$ & $9270(26.6 / \mathrm{pt})$ & 2.0 & $1455(4.2 / \mathrm{pt})$ \\
\hline & 157 lost & 567 lost & & 47 lost; 247 new \\
\hline
\end{tabular}

PT $=$ patient; Proj. $=$ number of projections. 


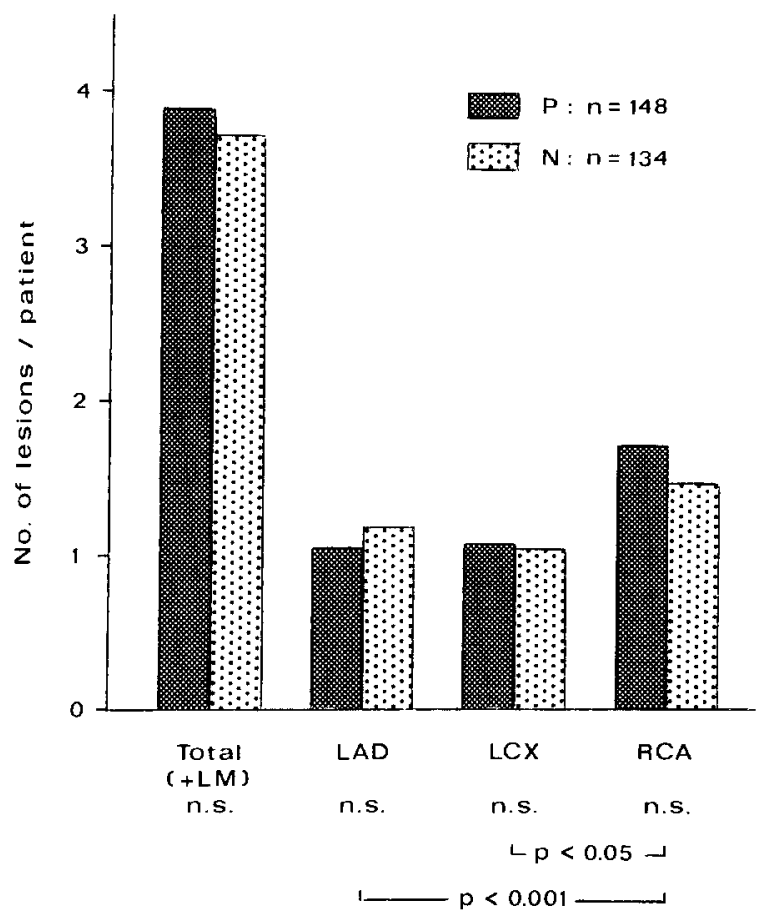

Fig. 2. Average number of coronary lesions (stenoses and occlusions) per patient in the inclusion angiograms of patients on nifedipine (N) and on placebo (P) and distribution of lesions among the three major coronary arteries; $\mathbf{L M}=$ left main artery; $\mathrm{LAD}=$ left anterior descending artery; $\mathrm{LCX}=$ left circumflex artery; $\mathrm{RCA}=$ right coronary artery; ( $\mathrm{N}$ vs $\mathrm{P}$ : separate variance analysis).

In the 348 patients with two study angiograms each (groups I and II), a total of 4688 different segments (13.5 per patient) were compared between the two study angiograms (Table 2). Since the segments were measured in an average of 2.0 different (mostly nearly orthogonal) angiographic projections, a total of 9270 segment measurements from the inclusion angiograms were repeated at follow-up. Due to poor quality of the follow-up angiograms or to occlusions of previously patent segments, 157 segments and 567 segment measurements from the inclusion angiograms were lost for follow-up (Table 2).

A total of 1255 coronary lesions (an average of 3.6 per patient), i.e. 1105 stenoses and 150 occlusions, were detected in the inclusion angiograms (Table 2). Twenty stenoses were lost for follow-up due to poor film quality, another 27 due to new occlusions at sites located proximal to the known stenoses, i.e., a total of 47 stenoses were lost. Since 247 new lesions, 228 stenoses and 19 occlusions were found in the follow-up angiograms, a total of 1455 lesions (4.2 per patient) were finally analyzed (Table 2).

The following analysis of angiographic baselineand follow-up data will concentrate on the results of the 282 patients without relevant protocol violations (group I). In the patients on $\mathrm{N}$, an average of 3.7 lesions per patient (438 stenoses and 60 occlusions) were found in the inclusion angiograms versus 3.9 lesions per patient on P (507 stenoses and 67 occlusions) (n.s.). The distribution of the lesions among the three major coronary arteries is demonstrated in Fig. 2. In either group, the right coronary artery (RCA) presented more lesions when compared with the left anterior descending (LAD; $\mathrm{p}<0.001$ ) and left circumflex artery (LCX; $\mathrm{p}<0.05$ ), the differences between the study groups not being significant.

The changes in the parameters of all 3808 segments and the 945 preexisting stenoses analyzed in the group-I-patients over the study period of 3 years are presented in Table 3. For both treatment groups, the changes in the parameters were averaged in two ways: 1) from the individual mean values computed from the changes in all projections in which the parameters were analyzed in a patient; and 2) from the individual projections showing the greatest changes in the respective segment or stenosis parameters in the sense of progression of the disease. Segments and stenoses changing to occlusions were excluded in this analysis (see Table 1). In all parameters, the changes indicated progression of coronary artery disease $(p<0.006)$. However, when only the projections demonstrating the maximal change in a parameter in the sense of progression were considered, the changes were about three times greater in comparison to the average changes over all projections analyzed (Table 3). It is of particular relevance that - independent of any consideration of angiographic projections - no significant differences were observed between the treatment groups in the changes of any of the parameters.

Another mode of analysis of the progression or 
Table 3. Average changes in the angiographic parameters of 3808 segments and 893 stenoses $(N=404, P=489)^{1}$ between the two study angiograms in either study group according to two different modes of consideration of projections ${ }^{2}$.

\begin{tabular}{|c|c|c|c|c|c|c|c|c|c|c|}
\hline \multirow[t]{2}{*}{ Parameters } & \multicolumn{4}{|c|}{ Mean change over projections } & \multicolumn{4}{|c|}{ Maximal progression over projections } & \multirow{2}{*}{$\begin{array}{l}\mathrm{p} \\
\text { (1. vs } 2 . \\
\text { angiogram) }\end{array}$} & \multirow{2}{*}{$\begin{array}{l}\mathrm{p} \\
(\mathrm{N} \text { vs } \mathrm{P})\end{array}$} \\
\hline & $\mathbf{N}$ & & $\mathbf{p}$ & & $\mathrm{N}$ & & $\mathbf{P}$ & & & \\
\hline $\begin{array}{l}\text { Mean segment } \\
\text { diameter }(\mathrm{mm})\end{array}$ & $-0.03 \pm$ & 0.32 & $-0.03 \pm$ & 0.29 & $-0.15 \pm$ & 0.35 & $-0.14 \pm$ & 0.32 & $<0.006$ & n.s. \\
\hline $\begin{array}{l}\text { Min. segment } \\
\text { diameter }(\mathrm{mm})\end{array}$ & $-0.05 \pm$ & 0.33 & $-0.05 \pm$ & 0.31 & $-0.18 \pm$ & 0.37 & $-0.19 \pm$ & 0.35 & $<0.001$ & n.s. \\
\hline $\begin{array}{l}\text { Min. stenosis } \\
\text { diameter (mm) }\end{array}$ & $-0.05 \pm$ & 0.32 & $-0.07 \pm$ & 0.35 & $-0.15 \pm$ & 0.35 & $-0.17 \pm$ & 0.40 & $<0.001$ & n.s. \\
\hline $\begin{array}{l}\text { Percent diameter } \\
\text { stenosis }(\%)\end{array}$ & $+2.78 \pm$ & 12.4 & $+2.36 \pm$ & 13.0 & $+7.62 \pm$ & 15.7 & $+6.81 \pm$ & 15.2 & $<0.001$ & n.s. \\
\hline $\begin{array}{l}\text { Length of stenosis } \\
(\mathrm{mm})\end{array}$ & $+0.51 \pm$ & 1.91 & $+0.47 \pm$ & 1.81 & $+1.28 \pm$ & 2.46 & $+1.30 \pm$ & 2.47 & $<0.001$ & n.s. \\
\hline $\begin{array}{l}\text { Area plaque } \\
(\mathrm{mm} \times \mathrm{mm})\end{array}$ & $+0.71 \pm$ & 3.23 & $+0.61 \pm$ & 3.37 & $+1.91 \pm$ & 4.09 & $+1.77 \pm$ & 3.99 & $<0.001$ & n.s. \\
\hline $\begin{array}{l}\text { Stenoses changing } \\
\text { to occlusions }\end{array}$ & 9 & & 9 & & 9 & & 9 & & & n.s. \\
\hline
\end{tabular}

$\mathrm{N}=$ nifedipinc; $\mathrm{P}=$ placebo.

${ }^{1}$ Fifty-two stenoses of the inclusion angiograms were excluded: 38 stenoses were lost, 18 changed to occlusions ( 4 occlusions recanalized to stenoses).

${ }^{2}$ Except preexisting occlusions and changes of stenoses to occlusions.

regression of the stenoses in group I-patients is demonstrated in Tables 4 and 5 . In this case, only a change in the minimal stenosis diameter exceeding $\pm 0.4 \mathrm{~mm}$ or in percent diameter stenosis exceeding $\pm 20 \%$ was regarded as definite stenosis progression or regression; stenoses changing to occlu- sions were excluded. When the mean changes of all projections analyzed in the individual patients were considered, $8-15 \%$ of the stenoses of either group showed progression, and 3-7\% showed regression ( $\mathrm{N}$ vs P: n.s.; Table 4). When only the projections indicating the maximal progression or

Table 4. Progression and regression ${ }^{1}$ of 404 preexisting stenoses in 134 patients on $\mathrm{N}$ and of 489 stenoses in 148 patients on $\mathrm{P}^{2}$.

No. of stenoses

\begin{tabular}{lllll}
\hline Mean change over projections & & \multicolumn{3}{l}{ Maximal progression/regression over projections } \\
& $\mathrm{P}$ & $\mathrm{N}$ & $\mathrm{P}$ & $\mathrm{p}$ \\
& & & & $(\mathrm{N}$ vs P)
\end{tabular}

Change in minimal

stenosis diameter

Progression (decrease)

Regression (increase)

Change in percent

diameter stenosis

Progression (increase) $\quad 38(9.4 \%)$

Regression (decrease)

$$
43(10.6 \%)
$$

$24(5.9 \%)$

$14(3.5 \%)$

$$
\begin{aligned}
& 74(15.1 \%) \\
& 35(7.2 \%)
\end{aligned}
$$

$38(7.8 \%)$

$24(4.9 \%)$
$77(19.1 \%)$
$52(12.9 \%)$

$71(17.6 \%)$

$25(6.2 \%)$

$\begin{array}{rr}120(24.5 \%) & \text { n.s. } \\ 66(13.5 \%) & \text { n.s. }\end{array}$

$78(15.9 \%)$ $44(9.0 \%)$ n.s.

n.s.

\footnotetext{
${ }^{1}$ Progression/regression of stenosis $=$ change in minimal stenosis diameter exceeding $\pm 0.4 \mathrm{~mm}$ or exceeding percent diameter stenosis in $\pm 20 \%$. ${ }^{2}$ Except preexisting occlusions and changes of stenoses to occlusions.
} 
regression of a stenosis were considered, progression as well as regression were more frequent with $16-24 \%$ and $6-13 \%$ of stenoses, respectively ( $\mathrm{N}$ vs P: n.s.; Table 4).

According to the same two modes of definition of stenosis progression or regression (change in stenosis diameter exceeding $\pm 0.4 \mathrm{~mm}$ or in percent diameter stenosis exceeding $\pm 20 \%$ ), the groups of patients with at least one stenosis revealing progression or regression were analyzed (excluding stenoses changing to occlusions) (Table 5). When the mean changes over all projections analyzed in the individual patients were considered, progression was observed in $19-32 \%$ of the patients, regression in $10-21 \%$ of the patients and the combination of both in $2-4 \%$ of the patients ( $\mathrm{N}$ vs P: n.s.). Again, progression and regression were observed more frequently when only the projections demonstrating the maximal progression or regression were taken into account (Table $5 ; \mathrm{N}$ vs P: n.s.).

In the follow-up angiograms of the 282 patients of group I, a total of 196 new lesions (185 stenoses and 11 occlusions) were detected at arterial sites previously defined as normal. In 54 out of the 134 patients on $\mathrm{N}(40 \%), 72$ new stenoses and 6 occlu- sions were found versus 113 new stenoses and 5 occlusions in 73 out of the 148 patients on $\mathrm{P}(49 \%$; n.s.), i.e. an average of 0.58 lesions per patient on $\mathrm{N}$ versus 0.8 lesions per patient on $\mathrm{P}(-27 \% ; \mathrm{p}=$ 0.031 ; Fig. 3). When the distributions of the new lesions in the three major coronary arteries were analyzed with respect to the two treatment groups, a significant difference between the $\mathrm{N}$ - and P-group was observed in the LAD (0.13 lesions per patient on $\mathrm{N}$ versus 0.22 lesions per patient on $\mathrm{P} ;-40 \%$; $\mathrm{p}=0.047)$ and the LCX (0.16 versus 0.26 lesions per patient; $-38 \% ; p=0.035$ ). In the RCA, the vessel with the highest number of preexisting lesions, the highest number of newly formed lesions was detected. However, in this artery the difference between the treatment groups was not statistically significant $(0.27$ versus 0.29 lesions per patient; $-8 \% ; p=0.38$ ). (Fig. 3).

When all 348 patients with and without protocol violations who underwent two study angiograms, were considered in the analysis of data, again no significant differences were found between the two study groups with regard to changes in preexisting lesions [35]. The significant difference between the two treatment groups in the number of new lesions per patient, however, was confirmed by this 'in-

Table 5. Number of patients with at least one stenosis undergoing definite progression or regression ${ }^{1}$.

No. of patients

\begin{tabular}{|c|c|c|c|c|}
\hline \multicolumn{2}{|c|}{ Mean change over projections } & \multicolumn{3}{|c|}{ Maximal progression/regression over projections } \\
\hline $\begin{array}{l}N \\
(n=134)\end{array}$ & $\begin{array}{l}P \\
(n=148)\end{array}$ & $\begin{array}{l}\mathrm{N} \\
(\mathrm{n}=134)\end{array}$ & $\begin{array}{l}P \\
(n=148)\end{array}$ & $\begin{array}{l}P \\
(N \text { vs } P)\end{array}$ \\
\hline
\end{tabular}

Change in minimal

stenosis diameter

Progression (decrease)

Regression (increase)

Progression + regression

no change

Change in percent

diameter stenosis

\section{Progression (increase)}

Regression (decrease)

Progression + regression

no change

$33(25 \%)$
$22(16 \%)$
$6(4 \%)$
$85(63 \%)$

$$
\begin{array}{r}
30(22 \%) \\
13(10 \%) \\
3(2 \%) \\
94(70 \%)
\end{array}
$$

$47(32 \%)$
$31(21 \%)$
$6(4 \%)^{2}$
$76(51 \%)$

$54(40 \%)$
$42(32 \%)$
$8(6 \%)$
$46(34 \%)$

$\begin{array}{cr}28(19 \%) & 53(40 \%) \\ 22(15 \%) & 22(16 \%) \\ 3(2 \%)^{2} & 4(3 \%) \\ 101(68 \%) & 63(47 \%)\end{array}$

$\begin{array}{ll}60(41 \%) & \text { n.s. } \\ 49(33 \%) & \text { n.s. } \\ 10(7 \%)^{2} & \text { n.s. } \\ 49(33 \%) & \text { n.s. }\end{array}$

${ }^{1}$ For definitions see Table 4; stenoses changing to occlusions are excluded.

${ }^{2}$ Patients with both regression and progression are also listed among the patients with progression or regression. 


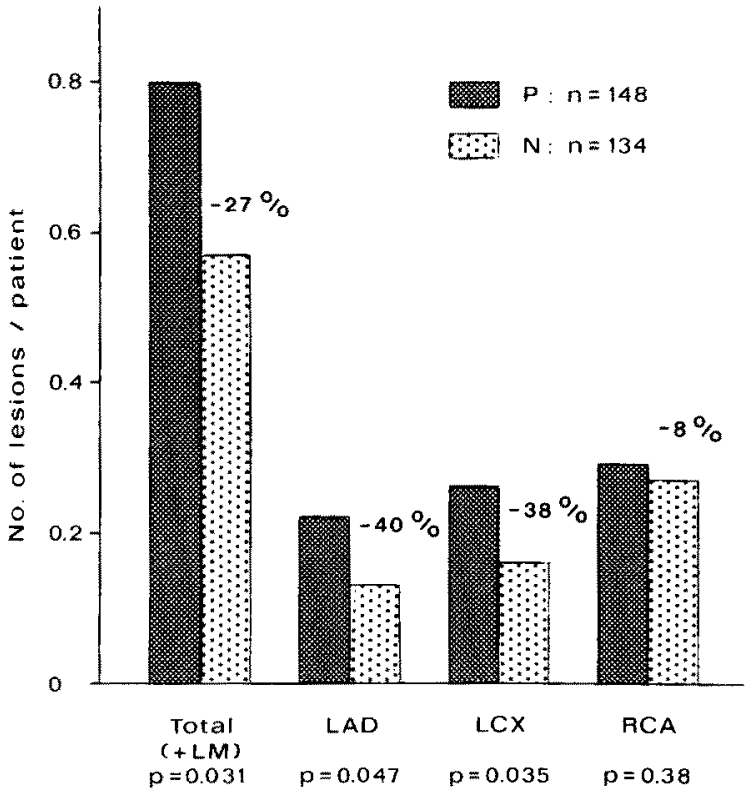

Fig. 3. Average number of new coronary lesions per patient detected in the follow-up angiograms of the 282 patients without protocol violations (group I) and distribution among the three major coronary arteries (abbreviations see Fig. 1). (Cochran's test for linear trend).

tention to treat' evaluation mode. Of 247 newly formed lesions, 228 stenoses and 19 occlusions, 103 were detected in the N-group and 144 in the Pgroup corresponding to an average of 0.59 new lesions per patient on $\mathrm{N}$ and of 0.82 lesions per patient on $\mathrm{P}(-28 \% ; \mathrm{p}=0.017$; Fig. 4).

During the study period coronary risk factors such as smoking or arterial hypertension had diminished significantly in patients of either treatment group, the differences between the groups being not significant. Total cholesterol levels remained unchanged in either group $[35,36]$.

\section{Discussion}

Since the end of the nineteen seventies, experiments have been performed with rabbits fed with an atherogenic diet which demonstrated an inhibition of the development of aortic atherosclerotic lesions with various calcium channel blockers [2730]. In most of these experiments, the drugs were

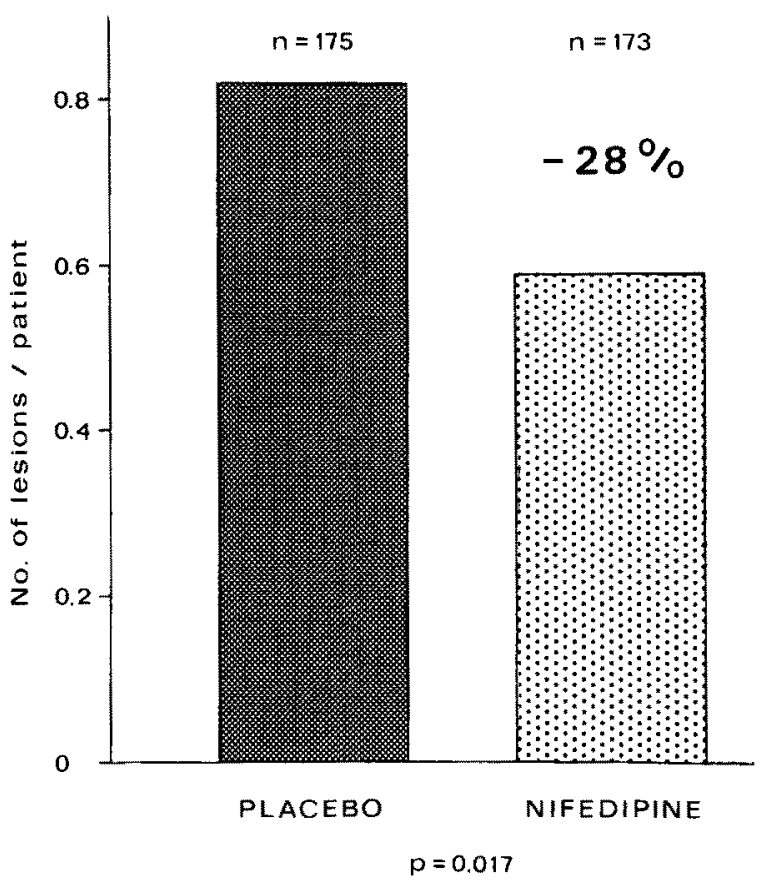

Fig. 4. Average number of new coronary lesions per patient in all 348 patients with two angiograms (groups I and II) (Cochran's test for linear trend).

administered in doses much higher than those tolerated by man $[27-29]$. Only nifedipine proved to inhibit the formation of atherosclerotic lesions in a dosage which can be administered in man $-0.1 \mathrm{mg}$ / $\mathrm{kg}$ bodyweight given orally [30]. Therefore, the identical drug regimen was applied in the INTACT study. In the rabbit model, the calcium channel blockers were demonstrated to inhibit the development of early atherosclerotic cholesterol-rich lesions [27-30]. Consequently, in INTACT the main emphasis was focussed on the influence of nifedipine on the formation of new stenoses. Nonetheless, the changes in preexisting stenoses were of great interest and were analyzed as well. However, progression of stenoses to occlusions was analyzed separately, since it represents a consequence of thrombosis rather than of atherosclerosis.

There is one major limitation in angiographic studies in general, being that only such changes in the coronary arterial wall can be documented and measured which result in a reduction in the diameter of the vessel lumen. In INTACT, atherosclerotic lesions which did not cause a diameter reduc- 
tion of at least $20 \%$ in at least one angiographic projection in the baseline angiograms were neglected. This 'threshold' was selected with respect to the limited accuracy of coronary angiography in general $[40,41]$ and to the known variability in repeated analyses of angiograms with the CAAS system in particular $[23,25]$.

The results of INTACT suggest an effect of nifedipine on the development of atherosclerotic lesions in man similar to that observed in animals. The effects on new coronary lesions were not only observed in patients who took the drug over the entire period of three years, but also in patients treated for only about one year on average. The suppression of the formation of new lesions in these patients underlines the antiatherosclerotic potential of the calcium channel blocker, although this collective was rather small. Therefore, when the data were analyzed according to the intention to treat' principle, the drug effects became even more apparent. It is of particular importance to mention that the risk factor profiles before and during the study were not different between the two treatment groups and could, therefore, not contribute to the differences in the progression of coronary sclerosis $[35,36]$.

The inhibitory effect of nifedipine on the development of new atherosclerotic lesions was limited to the LAD and LCX artery and was not observed in the RCA. One reason for this observation may be that already in the inclusion angiograms, the RCA presented the highest number of preexisting lesions, i.e. with the most advanced atherosclerosis. Less 'normal' coronary segments could mean less targets for the protective effect of nifedipine. The number of newly formed lesions was also highest in the RCA as already observed in previous studies [42-44]. One explanation may be that blood flow which has been shown to be different between the three large coronary arteries, could play a role in the development and progression of coronary atherosclerosis $[45,46]$.

To date, there is only one study on the effect of a calcium channel blocker on the progression of coronary atherosclerosis in man which may be comparable to INTACT [17]. Using a retrospective film analysis, the authors found a significant inhibition of the formation of new coronary stenoses in patients treated with the dihydropyridine nicardipine. As in our study on nifedipine, preexisting coronary stenoses were not influenced by nicardipine [17]. In another study, comparing the effects of nifedipine on coronary atherosclerosis with those of isosorbide dinitrate and propranolol, the calcium channel blocker was demonstrated to inhibit the formation of new lesions as well as the progression of preexisting stenoses [47]. However, this study did not use a randomized and double blind protocol.

It is a limitation of many previously published angiographic studies on the progression of coronary artery disease, that the main interest was focussed upon preexisting stenoses rather than on the formation of new angiographically recognizable lesions $[12-14,43,44,48-53]$. This is a point of extraordinary interest, since interventions which may influence the formation of early lesions, e.g. by an effect on the cholesterol uptake into the vascular endothelium, do not necessarily influence the progression of preexisting stenoses. Today, progression of already established stenoses is regarded to be associated with adhesion of platelets which excrete potent tissue growth factors provoking proliferation of smooth muscle cells and connective tissue, i.e. growth of the plaque [54]. In animal experiments, the mere presence of a stenosis proved to be sufficient to provoke platelet adhesion [55]. Plaque rupture with consecutive thrombus formation, as documented in patients with unstable angina or myocardial infarction, may play an additional role in the progression of preexisting stenoses $[56$, 57]. Hence, mechanisms for the formation of new lesions on the one hand and for the progression of established lesions on the other hand may be different.

In some INTACT-patients with multiple preexisting stenoses, progression as well as regression was observed. That means that different stenoses in the identical patient were subject to contrary developments in spite of a common exposition to coronary risk factors as nicotine, cholesterol, hypertension, etc. or to a potentially protective substance as nifedipine. Therefore, other factors may additionally influence the progression and regres- 
sion of preexisting lesions, as for instance, the location of a stenosis with regard to bends or ramifications, or the shape, i.e. the taper of the surface of a stenosis [46].

In INTACT, the average changes in the angiographic parameters of the preexisting stenoses were relatively small when compared to similar investigations [58]. In addition, only about $40 \%$ of the patients revealed definite progression of at least one stenosis, when changes of more than $0.4 \mathrm{~mm}$ in stenosis diameter or of more than $20 \%$ in stenosis severity were defined as progression or regression. This indicates a much lower progression rate than found in previous studies which usually defined stenosis progression as an increase in percent stenosis by at least $20 \%$ as assessed by visual film inspection $[10,42,43,50,59,60]$. One reason may be that - in contrast to INTACT - these studies mainly selected symptomatic patients in a retrospective mode. In addition, in contrast to most of these previous studies, patients with moderate coronary atherosclerosis were preferably included in INTACT.

Except for INTACT, only one angiographic follow-up study has been performed in which coronary angiograms were repeated in exactly identical projections [15]. However, in this study, progression of coronary artery disease was assessed by visual inspection. It has been shown that only by observation of absolutely identical angiographic projections, major errors emerging from even slightly different views can be circumvented [61].

In the present study, coronary segments were analyzed quantitatively in an average of as many as two different (mostly nearly orthogonal) angiographic projections. Therefore, the calculation of a mean change over all projections performed was possible on the one hand, and a selection of the projection with the most profound change on the other hand. When only the projections with the most profound changes in the sense of progression were considered, the average progression of all parameters was substantially greater when compared to the calculation of average changes over all projections. The same difference was found, when the number of definitely progressive stenoses and of patients with such stenoses were compared. It should be considered, however, that, when only the projection indicating the maximal progression is taken into the calculation, most of the errors of the method which result in an overestimation of progression may be selected, and most of the errors resulting in an underestimation of progression may be neglected. That means that this mode of evaluation can result in an overestimation of the true progression of coronary artery disease. On the other hand, information is lost when the changes are averaged over all projections. Calculation of the percent area stenosis, i.e. of the percentage reduction in the vessel's cross section by the atherosclerotic plaque, would be the perfect solution. However, percent area stenosis cannot be measured reliably with contour detection systems. Even when multiple views are available, the area stenosis of 'complicated' stenoses, i.e. of stenoses with an asymmetric lumen, is difficult to assess with this method [61,62]. Therefore, the observation of numerous angiographic projections and consideration of the projection with the maximal change seems to be the most appropriate mode to assess progression (or regression) of coronary atherosclerosis with an edge detection system as CAAS. One alternative available today is cine-video-densitometry which is supposed to measure the percent area stenosis from only one view. However, there are still many methodologic problems in cine-videodensitometry which shall not be discussed here [6366].

The goal of INTACT was to test, whether progression of coronary artery disease can be slowed down with nifedipine. Regression was not a primary endpoint, but was observed in some patients. It is still a subject of discussion, whether 'regression' in the sense of reduction of a manifest plaque is really possible [67-70]. Angiographically proven reduction of percent stenosis or increase in stenosis diameter does not necessarily mean reduction of the plaque. The media of atherosclerotic arterial segments is known to become thinner, resulting in dilation of the vessel lumen; this may pretend 'regression' [71-73]. Furthermore, thrombus adhesion to a stenosis in one angiogram might have disappeared in the next one imposing as 'regression'. In future studies with intracoronary echoar- 
teriography or with magnetic resonance imaging (MRI), it might be possible to determine the true plaque dimensions [74-76]. That means that differentiation between actual plaque regression and 'pseudo regression' could be possible. In addition, it could be possible to perform a more sophisticated analysis of plaque growth and composition with intracoronary echoarteriography.

INTACT is the first angiographic follow-up study in which strict attempts were made to create a comparable, i.e. a standardized coronary vasomotor tone. This was achieved by administration of a high dose of isosorbide dinitrate which induces nearly maximal coronary vasodilation [37]. Influences of other vasoactive substances were avoided, since they were withheld two days before angiography. The variability of the coronary vasomotor tone has not been considered in previous investigations of the reproducibility of the assessment of coronary dimensions with the CAAS system in the same patients after an interval of days or months [23]. When in similar investigations with the CAAS system coronary vasodilation had been induced prior to repeated angiograms, the standard deviation values of the mean differences between the measurements were found to be considerably lower [23]. Based on these data, a stenosis was arbitrarily defined by a diameter reduction of at least $20 \%$ (approx. threefold standard deviation). In addition, the threshold for definite progression and regression of coronary artery disease was fixed at a percent diameter stenosis of $20 \%$ and at a stenosis diameter of $0.4 \mathrm{~mm}$ (approx. twofold standard deviation). The definition of a stenosis as diameter reduction of as much as at least $20 \%$ might have led to a drop-out of true (i.e. falsely negative) stenoses caused by an atherosclerotic plaque. However, this high threshold has prevented the inclusion of too many stenosis artifacts (i.e. falsely positive stenoses) in the data bank.

Some of the angiographic stenosis parameters analyzed in INTACT, e.g. interpolated percent diameter stenosis and plaque area, depend on the assumption of 'normal' adjacent subsegments, a precondition which is not always realized. Nonetheless, in both treatment groups these parameters indicated the progression of coronary artery dis- ease to a similar degree as did the diameter measurements. In previous studies, absolute parameters were shown to indicate the progression of coronary artery disease more reliably than derived parameters [58]. Anyhow, in INTACT a stenosis was not defined as absolute change in the arterial diameter - for example of at least $0.4 \mathrm{~mm}$ - but in percentage diameter reduction of at least $20 \%$. The reason was that in segments with diameters ranging from $1 \mathrm{~mm}$ to $6 \mathrm{~mm}$ - as in INTACT - a diameter reduction of for instance $0.4 \mathrm{~mm}$ would correspond with a percentage diameter reduction ranging widely from as little as $7 \%$ to as much as $40 \%$. Maybe, the combination of either a localized diameter reduction by $\geqslant 0.4 \mathrm{~mm}$ and/or a percent diameter stenosis $\geqslant 20 \%$ would be a more sensitive but still arbitrary - definition of a coronary stenosis.

In addition to the 15 different coronary segments defined by the American Heart Association [39], analysis of 10 further segments was possible in INTACT. They were only selected in anatomic variants (dominance of one artery). A segment diameter of $1 \mathrm{~mm}$ was the smallest that was accepted, since contour detection systems could not reliably measure smaller vessel diameters $[24,77,78]$. Due to the wide spectrum of segment diameters measured in INTACT, the progression of coronary artery disease and its modification by nifedipine can also be differentiated with regard to the caliber of the segments; this will be the subject of future analyses.

In no previous coronary angiographic studies as many arterial segments were quantitatively analyzed as in INTACT $[14,58]$. A number of segments could not be reanalyzed in the follow-up angiograms due to occlusions of the segments themselves or of proximal segments. In addition, data of few segments and stenoses were lost in the follow-up angiograms due to poor film quality. Nonetheless, the high number of an average of 13.5 different segments per patient compared between the angiograms proves that quantitative analysis of repeated coronary angiograms is highly reproducible when identical projections are compared.

Despite the relatively objective method to analyze contours of coronary segments with an automated system, there were numerous subjective 
moments in the comparison of repeated coronary angiograms in INTACT. The selection of appropriate segments, projections, and film frames had to be done by an experienced specialist; so far, no algorithm is able to make these decisions. Sometimes, manual contour corrections were necessary in the presence of ramifications of segments or of short overlaps; so far, these pitfalls cannot be recognized by an algorithm. In addition, new stenoses had to be detected primarily by the investigator who had the task to identify the stenoses, even when hidden in ramifications or behind overlaps, i.e. when visible in only one or few frames. Artifacts, e.g. caused by muscle bridges, temporary lack of contrast or in bends had to be differentiated from (probably) truly atherosclerotic lesions. The stenoses suggested by the analyzer had to be verified with the automated measurement. It is likely that a number of true stenoses have been missed in INTACT and that the subjective criteria mentioned above led to errors. However, these errors would be distributed similarly among the study groups and, therefore, can not influence the conclusiveness of the study results.

The following sources of error may also have contributed to inaccuracies in the results: 1) Calibration of the cine frames with the help of the coronary catheter (although actual catheter dimensions were available); 2) pincushion distortion (which was corrected for the most part by a special algorithm [23]; 3) comparison of segments not being in absolutely identical positions in the image planes [25]; 4) problematic reproducibility of an identical inspiratory state of the patients $[26,79] ; 5)$ nonlinear behaviour of the transfer function of the cinefilm, quantum noise of the images, electronic noise contributions in the analog to digital conversion etc. [23]. All these limitations were considered in the variability of the method as already published [23].

The following conclusions may be drawn from the results and the methodologic experiences from INTACT:

1. An inhibitory effect of nifedipine on the formation of new atherosclerotic lesions in human coronary arteries is highly probable. Nifedipine seems to have no influence on the further devel- opment of preexisting stenoses. Additional prospective coronary angiographic studies with calcium channel blockers should be undertaken to confirm the results of INTACT.

2. In this prospective angiographic analysis of patients with moderate coronary artery disease, the progression of the disease has been shown to develop more slowly than demonstrated in previous retrospective trials.

3. In studies on interventions influencing the progression of coronary artery disease, more attention should be focussed on an important characteristic of progression - the formation of new atherosclerotic lesions.

4. Elimination of a variable coronary vasomotor tone with vasodilating agents and comparison of absolutely identical angiographic projections should be prerequisites for angiographic followup studies.

5. In multicenter coronary angiographic follow-up trials, strict quality control of all angiograms should take place in the core center of film analysis before inclusion of any patient into the study. This could allow for opportune rejection of films with suboptimal quality and could lead to analysis of even more segments in more angiographic projections than in INTACT.

6. To further increase the number of segments and of different views for analysis, a high number of different axial and half-axial angiographic projections (eventually with recommendation of definite projection angles) should be mandatory in future coronary angiographic follow-up trials with quantitative geometrical cinefilm analysis.

7. The double-blind feature of studies like INTACT is essential to allow for conclusive results despite numerous limitations of the present methods.

\section{Acknowledgement}

The authors wish to thank Mrs. Jutta Graca for her secretarial assistance. 


\section{Appendix}

\section{Centers participating in INTACT}

Germany:

1. Medizinische Hochschule Hannover

PR Lichtlen, W Rafflenbeul, S Jost, P Nikutta, U Nellessen, B Schneider, H Hecker, B Wiese

2. Universitätsklinikum Eppendorf, Hamburg

W Bleifeld, C Hamm, W Kupper

3. Zentralkrankenhaus 'Links der Weser', Bremen

HJ Engel, $\mathrm{H}$ Werner

4. Universitätsklinik Charlottenburg, Berlin

H Schmutzler, H Bias

5. Universitätsklinikum Frankfurt

M Kaltenbach, G Kober, H Klepzig, D Kneissl

6. Medizinische Poliklinik der Universität Erlangen

K Bachmann, S Haetinger

The Netherlands:

7. Academisch Ziekenhuis Dijkzigt, Thoraxcentrum Rotterdam PG Hugenholtz, JW Deckers, JHC Reiber, K Laird-Meeter, PW Serruys

8. Catharina-Hospital, Eindhoven

JJRM Bonnier, RHR Michels, J Troquay

9. Academisch Ziekenhuis Groningen

KI Lie, ED De Muinck, J Posma

\section{References}

1. The Coronary Drug Project Research Group. Clofibrate and niacin in coronary heart disease. JAMA 1975; 231: $360-81$.

2. Multiple Risk Factor Intervention Trial Research Group. Multiple risk factor intervention trial. JAMA 1982; 248: 1546-77.

3. Lipid Research Clinics Program. The lipid research clinics coronary primary prevention trial results. JAMA 1984; 251: $351-64$.

4. Kromhout D, Bosschieter EB, Lezenne Coulander C. The inverse relation between fish consumption and 20 year mortality from coronary heart disease. N Engl J Med 1985; 312 : $1205-9$

5. Kushi LH, Lew RA, Stare FJ, Ellisson CR, El Lozy M, Bourke G, Daly L, Graham I, Hiday N, Mulcahy R, Kevaney $R$. Diet and 20-year mortality from coronary heart disease. N Engl J Med 1985; 312; 811-8.

6. Gordon DJ, Knoke J, Probstfield JL, Superko R, Tyroler HA. High-density lipoprotein cholesterol and coronary heart disease in hypercholesterolemic men: The lipid research clinics coronary primary prevention trial. Circulation 1986; 6: 1217-25.

7. Anderson KM, Castelli WP, Levy D. Cholesterol and mor- tality; 30 years of follow-up from the Framingham study. JAMA 1987; 257:2176-80.

8. Frick MH, Elo O, Haapak M, Heinonen OP et al. Helsinki heart study: primary-prevention trial with Gemfibrozil in middle aged men with dyslipidemia. N Engl J Med 1987; 317: $1237-45$.

9. Abbott RD, Wilson PWF, Kannel WB, Castelli WP. High density lipoprotein cholesterol, total cholesterol screening, and myocardial infarction. Arteriosclerosis 1988; 8: 207-11.

10. Nash DT, Gensini G, Simon H, Arno T, Nash SD. The Erysichthon syndrome; progression of coronary atherosclerosis and dietary hyperlipidemia. Circulation 1977; 56: 363-5.

11. Rafflenbeul W, Smith LR, Rogers WJ, Mantle JA, Rackley LE, Russel RO. Quantitative coronary angiography: coronary anatomy of unstable angina pectoris one year after optimal medical therapy. Am J Cardiol 1979; 43: 699-707.

12. Brensike JF, Levy RI, Kelsey SF et al. Effects of therapy with cholestyramine on progression of coronary atherosclerosis: results of the NHLBI-type II coronary intervention study. Circulation 1984; 69: 313-24.

13. Levy RI, Brensike JF, Epstein STE. The influence of changes in lipid values induced by cholestyramine and diet on progression of coronary artery disease: results of the NHLBI-type II coronary intervention study. Circulation 1984; 69: 325-36.

14. Arntzenius $A C$, Kromhout D, Barth JD, Reiber JHC, Bruschke AVG, Buis B, van Gent CM, Kempen-Voogd N, Strikwerda S, van der Velde EA. Diet, lipoproteins and the progression of coronary atherosclerosis. The Leiden interventional trial. N Engl J Med 1985; 312: 805-11.

15. Blankenhorn DH, Nessim SA, Johnson RL, Sanmarco ME, Azen SP, Cahin Hemphill LC. Beneficial effects of combined colestipol-niacin therapy on coronary atherosclerosis and coronary venous bypass grafts. JAMA 1987; 257: 3233-40.

16. Brown BG, Lin JT, Schaefer SM, Kaplan CA, Dodge HT, Albers JJ. Niacin or lovastatin, combined with colestipol, regress coronary atherosclerosis and prevent clinical events in men with elevated apolipoprotein B. Circulation 1989; 4: II266 (Abstract).

17. Waters D, Lespérance J, Francetich M, Causey D, Théroux P, Chiang YK, Hudon G, Lemarbre L, Reitman M, Joyal M, Gosselin G, Dyrda I, Macer J, Havel R. A controlled clinical trial to assess the effect of a calcium channel blocker upon the progression of coronary atherosclerosis. Circulation 1990; 82: 1940-53.

18. Detre KM, Wright E, Murphy ML, Takaro T. Observer agreement in evaluating coronary angiograms. Circulation 1975; 52: 979-86.

19. Zir LM, Miller SW, Dinsmore RE, Gilbert JP, Harthorne JW. Interobserver variability in coronary angiography. Circulation 1976; 53: 627-32.

20. Galbraith JE, Murphy ML, de Soyza N. Coronary angiogram interpretation. JAMA 1978; 19: 2053-6.

21. Sanmarco ME, Brooks SH, Blankenhorn DH. Reproduc- 
ibility of a consensus panel in the interpretation of coronary angiograms. Am Heart J 1978; 96: 430-7.

22. Brown BG, Bolson E, Frimer M, Dodge HT. Quantitative coronary arteriography: estimation of dimensions, hemodynamic resistance, and atheroma mass of coronary artery lesions using the arteriogram and digital computation. Circulation 1977; 55: 329-37.

23. Reiber JHC, Serruys PW, Kooijman CJ, Wijns W, Slager $\mathrm{CJ}$, Gerbrands JJ, Schuurbiers JCH, den Boer A, Hugenholtz PG. Assessment of short-, medium-, and long-term variations in arterial dimensions from computer-assisted quantitation of coronary cineangiograms. Circulation 1985; 71: $280-8$.

24. Reiber JHC. Morphologic and densitometric quantitation of coronary stenoses; an overview of existing quantitation techniques. In: Reiber JHC, Serruys PW, eds. New developments in quantitative coronary arteriography. Kluwer Academic Publishers, Dordrecht, Boston, London. 1988: 34-88.

25. Reiber JHC, van Eldik-Helleman P, Visser-Akkerman N, Kooijman CI, Serruys PW. Variabilities in measurement of coronary arterial dimensions resulting from variations in cineframe selection. Cathet Cardiovasc Diagn 1988; 14 : 221-8.

26. Reiber JHC, den Boer A, Serruys PW. Quality control in performing quantitative coronary arteriographic studies. Am J Cardiac Imaging 1989; 172-9.

27. Henry PD, Bentley K. Suppression of atherosclerosis in cholesterol-fed rabbits treated with nifedipine. J Clin Invest 1981; 68: 1366-9.

28. Rouleau JL, Parmley WW, Stevens J, Wikman-Coffelt $J$, Sicvers R, Mahley RW, Havel RJ. Verapamil suppresses atherosclerosis in cholesterol-fed rabbits. J Am Coll Cardiol 1983; 6: 1453-60.

29. Willis AL, Nagel B, Churchill V, Whyte MA, Smith DL, Mahmud I, Puppione DL. Anti-atherosclerotic effects of nicardipine and nifedipine in cholesterol-fed rabbits. Arteriosclerosis 1985; $5: 250-5$.

30. Nayler WG, Dillon JS, Panagiotopoulos S, Sturrock WJ. Dihydropyridines and the ischaemic myocardium. In: Lichtlen PR, ed., 6th Adalat Symposium. New Therapy of Ischemic Heart Disease and Hypertension. Amsterdam. Excerpta Medica 1986: 386-97.

31. Lichtlen PR, Nellessen U, Rafflenbeul W, Jost S, Hecker H. INTACT (International Nifedipine Trial on Antiatherosclerotic Therapy). Cardiovasc Drugs Ther 1987; 1: 71-9.

32. Jost S, Deckers J, Nellessen U, Rafflenbeul W, Hecker H, Reiber JHC, Hugenholtz PG, Lichtlen PR. Clinical application of quantitative coronary angiography - preliminary results of the INTACT-study (International Nifedipine Trial on Antiatherosclerotic Therapy). Int J Cardiac Imaging $1988 ; 3: 75-86$.

33. Jost S, Deckers J, Nellessen U, Rafflenbeul W, Hecker $H$, Reiber JHC, Lippolt P, Hugenholtz PG, Lichtlen PR. Computer-assisted contour analysis technique in coronary angiographic follow-up trials: results of the first angiograms from the INTACT-study. Z Kardiol 1989; 78: 23-32.

34. Lichtlen PR, Hugenholtz PG, Jost S. International nifedipine trial on antiatherosclerotic therapy (INTACT) - baseline data and preliminary results. Therap Res 1989; 10: 77-102.

35. Lichtlen PR, Hugenholtz PG, Rafflenbeul W, Hecker H, Jost S, Deckers JW. Retardation of the angiographic progression of coronary artery disease in man by the calcium channel blocker nifedipine - results of the international nifedipine trial on antiatherosclerotic therapy (INTACT). The Lancet 1990; 335: 1109-13.

36. Lichtlen PR, Hugenholtz PG, Rafflenbeul W, Hecker H, Jost S, Nikutta P, Deckers W. Retardation of the progression of coronary artery disease in man by nifedipine; the INTACT-study (International Nifedipine Trial on Antiatherosclerotic Therapy). Cardiovase Drugs Ther 1990; 4: 1047-68.

37. Jost S, Rafflenbeul W, Reil GH, Gulba D, Knop I, Hecker H, Lichtlen PR. Reproducible uniform coronary vasomotor tone with nitrocompounds: Prerequisite of quantitative coronary angiographic trials. Cathet Cardiovasc Diagn $1990 ; 20: 168-73$.

38. Jost S, Deckers J, Rafflenbeul W, Hecker H, Nellessen U, Wiese B, Hugenholtz PG, Lichtlen PR. Features of the angiographic evaluation of the INTACT-study. Cardiovasc Drugs Ther 1990; 4: 1037-46.

39. Austen WG, Edwards JE, Frye RL, Gensini G, Gott VL, Griffith LSC, McGoon DG, Murphy ML, Roe BB. A reporting system on patients evaluated for coronary artery disease: report of the Ad Hoc Committee for Grading of Coronary Artery Disease, Council on Cardiovascular Surgery, American Heart Association. Circulation 1975; 51: 5-40.

40. Christensen EE, Curry IS III, Dowdey JE. An introduction to the physics of diagnostic radiology, 2nd ed. Philadelphia: Lea and Febiger, 1978: 158-70.

41. Arnett EN, Isner JM, Redwood DR, Kent KM, Baker WP, Ackerstein $\mathrm{H}$, Roberts WC. Coronary artery narrowing in coronary heart disease: comparison of cineangiographic and necropsy findings. Annals Intern Med 1979; $91: 350-6$.

42. Rösch J, Antonovic R, Trenouth RS, Rahimtoola SH, Sim DN, Dotter CT. The natural history of coronary artery stenosis. Radiology 1976; 119: 513-20.

43. Bruschke AVG, Wijers TS, Kolsters W, Landmann J. The anatomic evaluation of coronary artery disease demonstrated by coronary angiography in 256 nonoperated patients. Circulation 1981; 63: 527-30.

44. Kramer JR, Kitazume H, Proudfit WL, Matsuda Y, Coormastic M, Williams GW, Sones FM. Segmental analysis of the rate of progression in patients with progressive coronary atherosclerosis. Am Heart J 1983; 106: 1427-31.

45. Olinger GN, Mulder DG, Maloney JV, Buckberg GD. Phasic coronary flow: intraoperative evaluation of flow distribution, myocardial function, and reactive hyperemic response. Ann Thoracic Surg 1976; 21: 397-404. 
46. Schettler G, Nerem RM, Schmid-Schönbein H, Mörl H, Diehm C, eds. Fluid dynamics as a localizing factor for atherosclerosis. Springer-Verlag, Heidelberg, 1983: 1-226.

47. Loaldi A, Polese A, Montorsi P, De Cesare N, Fabbiocchi F, Ravagnani P, Guazzi MD. Comparison of nifedipine, propranolol and isosorbide dinitrate on angiographic progression and regression of coronary arterial narrowings in angina pectoris. Am J Cardiol 1989; 64: 433-9.

48. Cohn K, Sakai FJ, Langston MF. Effect of clofibrate on progression of coronary disease: a prospective angiographic study in man. Am Heart J 1975; 89: 591-8.

49. Kuo PT, Hayase K, Kostis JB, Moreyra AE. Use of combined diet and colestipol in long-term $(7-71 / 2$ years) treatment of patients with type II hyperlipoproteinemia. Circulation 1979; 2: 199-214.

50. Kramer JR, Matsuda Y, Mulligan JC, Aronow M, Proudfit WL. Progression of coronary atherosclerosis. Circulation 1981; 3: 519-26.

51. Nash DT, Gensini G, Esente P. Effect of lipid-lowering therapy on the progression of coronary atherosclerosis assessed by scheduled repetitive coronary arteriography. Intern J Cardiol 1982; 2: 43-55.

52. Moise A, Théroux $P$, Taeymans J, Waters DD, Lespérance $\mathrm{I}$, Fines $\mathrm{P}$, Descoings B, Robert $\mathrm{P}$. Clinical and angiographic factors associated with progression of coronary artery disease. J Am Coll Cardiol 1984; 3: 659-67.

53. Nikkilä EA, Viikinkoski P, Valle M, Frick MH. Prevention of progression of coronary atherosclerosis by treatment of hyperlipidaemia: a seven year prospective angiographic study. Br Med J 1984; 289: 220-3.

54. Ross R. The pathogenesis of atherosclerosis - an update. N Engl J Med 1986; 8: 488-500.

55. Folts JD, Gallagher K, Rowe GG. Blood flow reductions in stenosed canine coronary arteries: vasospasm or platelet aggregation? Circulation 1982; 65: 248-55.

56. Davies MJ, Thomas AC. Plaque fissuring - the cause of acute myocardial infarction, sudden ischaemic death, and crescendo angina. Br Heart J 1985; 53: 363-73.

57. Falk $\mathrm{E}_{\text {. Unstable angina with fatal outcome: dynamic coro- }}$ nary thrombosis leading to infarction and/or sudden death. Circulation 1985; 71: 699-708.

58. Ellis S, Sanders W, Goulet C, Miller R, Cain KC, Lespérance J, Bourassa MG, Alderman EL. Optimal detection of the progression of coronary artery disease: comparison of methods suitable for risk factor intervention trials. Circulation 1986; 74: 1235-46.

59. Gensini GG, Kelly AE. Incidence and progression of coronary artery disease. Arch Intern Med 1972; 129: 814-27.

60. Shub C, Vlietstra RE, Smith HC, Fulton RE, Elveback L. The unpredictable progression of symptomatic coronary artery disease. Mayo Clin Proc 1981; 56: 155-60.

61. Spears JR, Sandor T, Baim BS, Paulin S. The minimum error in estimating coronary luminal cross sectional area from cineangiographic diameter measurements. Cathet Cardiovasc Diagn 1986; 9: 119-32.

62. Serruys PW, Reiber JHC, Wijns W, van den Brand M,
Kooijman CJ, ten Katen HJ, Hugenholtz PG. Assessment of percutaneous transluminal coronary angioplasty by quantitative coronary angiography: diameter versus densitometric area measurements. Am J Cardiol 1984; 54; 482-8.

63. Seibert JA, Nalcioglu O, Roeck WW. Characterization of the veiling glare PSF in $\mathrm{x}$-ray image intensified fluoroscopy. Med Phys 1984; 11: 172-9.

64. Barrett $\mathrm{W}$, Boone J. The effect of beam hardening and scatter on videodensitometric determination of percent stenosis. IEEE 1985: 15-20.

65. Sanz ML, Mancini J, LeFree MT, Mickelsen JK, Starling MR, Vogel RA, Topol EJ. Variability of quantitative digital subtraction coronary angiography before and after percutaneous transluminal coronary angioplasty. Am J Cardiol 1987; 60: 55-60.

66. Katritsis D, Lythall DA, Anderson MH, Cooper IC, Klebb-Peploe MM. Assessment of coronary angioplasty by an automated digital angiographic method. Am Heart J 1988; 116: 1181-7.

67. Roth D, Kostuk WJ. Noninvasive and invasive demonstration of spontaneous regression of coronary artery disease. Circulation 1980; 62: 888-96.

68. Malinow MR, Blaton V. Regression of atherosclerotic lesions. Arteriosclerosis 1984; 4: 292-5.

69. Shepherd J, Packard CJ. Regression of coronary atherosclerosis: is it possible? Br Heart J 1988; 59: 149-50.

70. Blankenhorn DH, Kramsch DM. Reversal of atherosis and sclerosis; the two components of atherosclerosis. Circulation 1989; 79: 1-7.

71. Freudenberg H, Knieriem H-J, Möller C, Janzen C. Quantitative morphology of coronary arteriosclerosis and coronary insufficiency. Basic Res Cardiol 1974; 69: 161-203.

72. Isner JM, Donaldson RF, Fortin AH, Tischler A, Clarke RH. Attenuation of the media of coronary arteries in advanced atherosclerosis. Am J Cardiol 1986; 937-9.

73. Glagov S, Weisenberg E, Zarins C, Stankunavicius R, Kolettis GJ. Compensatory enlargement of human atherosclerotic coronary arteries. N Engl J Med 1987; 316: 1371-5.

74. McPherson DD, Hiratzka LF, Lamberth WC, Brandt B, Hunt M, Gieso RA, Marcus ML, Kerber RE. Delineation of the extent of coronary atherosclerosis by high-frequency epicardial echocardiography. N Engl J Med 1987; 316: 304-9.

75. Johnson MR, McPherson DD, Fleagle SR, Hunt MM, Hiratzka LF, Kerber RE, Marcus ML, Collins SM, Skorton DJ. Videodensitometric analysis of human coronary stenoses: validation in vivo by intraoperative high-frequency epicardial echocardiography. Circulation 1988; 77: 328-36.

76. Magnetic resonance and revival of arterial sclerosis (editorial). The Lancet 1990; 350: 139-40.

77. Le Free MT, Simon SB, Lewis RJ, Bates ER, Vogel RA. Digital radiographic coronary artery quantification. Comput Cardiol 1985: 99-106.

78. Mancini BJ, Higgins CHB. Digital subtraction angiography: a review of cardiac applications. Progr Cardiovasc Dis 1985; $28: 111-41$. 
79. Jost S, Rafflenbeul W, Lichtlen PR. Assessment of the vasomotility of epicardial coronary arteries with quantitative coronary angiography. Z Kardiol 1989; 78: Suppl 6, $143-8$.
Address for offprints:

S. Jost,

Abt. f. Kardiologie,

Medizinische Hochschule Hannover,

Konstanty-Gutschow-Str. 8,

3000 Hannover 61, Germany 